\title{
TRADUÇÕES DO CHOLO: PROJETOS DE SOCIEDADE ANDINA QUE EMERGEM DA PASSAGEM DA TRADIÇÃO DO MANCHAY PUYTU DA ORALIDADE PARA A FORMA ESCRITA
}

Rafael Simões Lasevitz ${ }^{1}$

\section{RESUMO}

Entre o século $X I X$ e o século $X X$, diversos escritores latino-americanos se aventuraram na criação de versões escritas da tradicional narrativa oral andina Manchay Puytu. Neste artigo, me proponho a analisar como algumas dessas versões refletiam projetos de sociedade concebidos por seus autores, e isso, particularmente em relação a um contexto de América Latina pós-colonial. Para isto, tomo como central a figura do cholo, o mestiço de brancos com ameríndios e herói das histórias do Manchay que, por sua posição ambígua, recebia grande parte do peso de expectativas do meio intelectual de cada época, ora positivas, ora negativas. Para desenvolver minha análise, faço uso de extensa pesquisa bibliográfica, assim como de certas ferramentas teóricas tiradas das ciências sociais que me permitem pensar o contexto pós-colonial em que tais "traduções do cholo" se inserem. Concluo com reflexões sobre o cholo na obra de Taboada Terán, apresentado como psicologicamente insustentável, além de sem lugar diante da colonialidade do poder da sociedade em que ainda vive, e aponto ainda a importância do Manchay Puytu, acima de tudo como estratégia de lembrança de um opressor passado colonial, o que é ressaltado pela imagem da quena, flauta andina de alto poder simbólico na cosmologia quéchua.

Palavras-chave: Tradição oral. Literatura andina. Cholo. Manchay Puytu. Póscolonial. Projetos de sociedade. Colonialidade do poder. Cosmologia quéchua. 


\title{
TRANSLATIONS OF THE CHOLO: THE EMERGENCE OF ANDEAN PROJECTS OF SOCIETY OUT OF THE CONVERSION OF THE MANCHAY PUYTU TRADITION FROM THE ORAL TO THE WRITTEN FORM
}

\begin{abstract}
Between the nineteenth and twentieth centuries, many Latin-American writers ventured themselves in the creation of written versions of the traditional Andean oral tale Manchay Puytu. In this article, I propose myself to analyse how some of these versions reflected projects of society conceived by their authors, and that, particularly in relation to a postcolonial Latin-American context in which they were inserted. To do so, I take as central to my reflections the image of the cholo, the Andean mestizo, protagonist hero of Manchay's narratives who, due to his ambiguous position, would receive a large part of the burden of the expectations of intellectual circles of different periods in the region, both positive and negative. In order to develop my analysis, I make use of an extensive bibliographical research, as well as certain theoretical tools that I borrow from the social sciences and that allow me to think the postcolonial context in which such "translations of the cholo" find themselves in. Finally, I conclude with reflections on the representation of the cholo in Taboada Terán's Manchay, presented as a psychologically unsustainable being with no place for himself vis-à-vis the coloniality of power of the society he still finds himself in. In the end, I also point out the importance of the Manchay tale above all as a strategy of remembrance of an oppressive colonial past, what is highlighted in most versions of the tale by the image of the quena ${ }_{2}$ an Andean flute of high symbolical power within Quechua cosmology.
\end{abstract}

Keywords: Oral tradition. Andean literature. Cholo. Manchay Puytu. Postcolonial. Projects of society. Coloniality of power. Quechua cosmology.

\section{INTRODUÇÃO}

"Materia primaria de unidad de toda literatura es el idioma", começa Mariátegui seu ensaio sobre o processo da literatura, o sétimo de seus Siete ensayos de 
interpretación de la realidad peruana (2006, p. 179). Mariátegui assim começa, e eu também o faço, em função da peculiaridade da situação da literatura peruana, como dos outros países americanos formados a partir de processos coloniais, gerando essa desconfortável situação na qual a literatura que recebe o título de literatura nacional acaba delimitada, desde o princípio, à língua dos colonizadores, no caso, o castelhano. À Mariátegui - marxista anti-colonialista, defensor de um país e de uma literatura que fossem, ambos e inevitavelmente, tomados pela grande maioria indígena que forma os países andinos - restava então fazer uma análise da peruanidade e da colonialidade dessa literatura, ora pendendo para um lado, ora para outro, assim como de suas rotas de escape - apesar do idioma que seria sempre, claro, ainda o castelhano.

Ou talvez nem sempre. O próprio Mariátegui logo reconhece, existiam também escritos literários tanto em quéchua quanto em aimara, as duas principais línguas indígenas da região, mas que além de transportada da oralidade à escrita através de alfabetizantes mãos - e ouvidos - coloniais, era ainda bastante rara, especialmente naquelas primeiras décadas de século XX. Nessas circunstâncias, o máximo que se podia obter em termos de literatura autóctone, que de alguma forma de rebelasse contra a metrópole, e que de alguma forma desatasse o inevitável nó que levava o próprio Mariátegui a dizer que a literatura peruana era "de irrenunciable filiación española" (2006, p. 180), era tentar acessá-la em seus veículos também autóctones, fora da escrita, nas tradições populares e na literatura oral.

Esta se demonstrou uma solução interessante para muitos criollos descendentes de espanhóis na América - tanto peruanos quanto bolivianos. Ali em meados de século XIX, em um Peru já em situação de pós-independência, porém ainda governado, enquanto república, pela mesma elite colonial, e em uma Bolívia em situação política bastante semelhante, a possibilidade de se utilizar do silêncio colonial dos povos andinos para fazer deste silêncio - e de sua quebra - um suporte que pudesse carregar diversas bandeiras políticas de uma elite intelectual criolla acabou se mostrando uma boa estratégia, e ganhando sua força. Não coincidentemente, é nesta época que surgem movimentos como o da aldea letrada quéchua (ESPINO, 2002), tentativa em conjunto de indígenas e mestiços que tiveram acesso à alfabetização, e principalmente de criollos bilíngues que tentavam, de uma forma ou outra, resgatar tradições orais indígenas e, de alguma forma, traduzir essas tradições para o mundo da literatura escrita. Entre tantas tradições e 
traduções, porém, volto meu foco agora para uma especificamente, ainda que tão pouco específica em seus tantos desdobramentos: o Manchay Puytu.

\section{PRIMEIRA VERSÃO ESCRITA: “LA QUENA”, DE GORRITI}

"Vale decir, la oralidad es un modo de representación desterritorializante, en el que la memoria se encuentra en permanente reformulación o viaje". O caráter viajante das tradições orais, tão bem apontado aqui por Cocimano (2006), me parece neste caso também poder se referir às desterritorializações empreendidas pela própria escrita justamente quando fazia ela própria um esforço de territorialização destas tradições, conferindo-lhes a rigidez do papel e das letras impressas. Tomadas por diversos autores em períodos também distintos, estas tradições orais eram facilmente apropriadas e postas a serviço de diferentes projetos de nação. De meados do século $\mathrm{XIX}$ até as últimas décadas do século $\mathrm{XX}, 0$ Manchay Puytu - originalmente um yaraví, espécie de canção de amor andina de origem pré-hispânica (NEUSTADT, 2007) - foi por diversas vezes reescrito, e a história trágica de amor do sacerdote católico cholo e sua amante já representaram ideais republicanos e iluministas, e até mesmo indigenistas em suas traduções mais recentes.

Assim, não deixa de ser curioso notar que a primeira tentativa de transporte das já itinerantes - como também difusas - falas sobre a popular história do Manchay Puytu para o mundo das letras castelhanas se tenha dado através de Juana Manuela Gorriti, uma argentina. Gorriti nasceu em Salta em 1818, filha de um importante político liberal local, mudando-se aos treze anos para Tarija na Bolívia quando sua família é forçada ao exílio pelo caudilho argentino Facundo Quiroga. Em um conturbado casamento com o futuro ditador - e depois presidente constitucional - boliviano Manuel Isidro Belzu, o início da carreira literária de Gorriti parece coincidir com o exílio de Belzu em Lima (BERG, 1990). Em 1845, enfim, Gorriti escreve La quena, obtendo bastante sucesso no que era ainda sua primeira novela. Em La quena (1865), Gorriti conta a história de amor entre Hernán de Camporeal, um jovem mestiço, e Rosa, filha do ouvidor local, ambientada em uma Lima de grandes tensões entre o poder metropolitano e conspirações anticoloniais. A família de Rosa, ao descobrir as origens indígenas de Hernán e suas pretensões em relação à jovem, resolve impedir sua união a qualquer custo, até ser enfim dado por 
morto. Livres da ameaça de Hernán, o pai de Rosa arranja-Ihe o casamento com o jovem e rico ouvidor Ramírez enquanto que Hernán, foragido, ao saber do casamento de Rosa com Ramírez e tomando-o por uma traição de Rosa ao seu amor, decide tornar-se sacerdote. Meses depois, retornando a Lima para praticar suas funções eclesiásticas, Hernán se encontra novamente com Rosa e, após confirmarem novamente seu amor um pelo outro, decidem enfim que fugiriam no dia seguinte. Naquela mesma noite, contudo, os planos dos dois amantes chegam a um final trágico quando Ramírez, sabendo de suas pretensões e querendo evitar a humilhação, mata a própria esposa. Ao contrário de outros autores ou tradutores, Gorriti evita narrar em detalhes a sequência final e prefere, sem muito se prolongar, saltar diretamente para a cena onde, já em seu quarto, Hernán contempla ao seu lado o corpo exumado de Rosa, agonizando de amor ao seu lado enquanto toca, com uma quena - espécie de flauta andina - feita com o próprio fêmur de sua amada, uma música sublime, simultaneamente doce e aterradora, que ainda que a autora não o explicite, fica claro tratar-se do Manchay Puytu.

\section{O CHOLO E SUAS DEFINIÇÕES}

Antes de seguir com todas estas indagações literárias, é importante que fique claro aqui - assim como é importante para qualquer história contada - quem é afinal o nosso herói neste Manchay Puytu? O personagem central da versão de Gorriti é Hernán Camporeal, um mestiço, ou seja, um cholo peruano filho de mãe indígena com um pai da nobreza espanhola - que abandona a mãe quando o filho ainda é

criança, levando-o consigo para estudar em Madrid. É desta centralidade que pretendo tratar daqui em diante neste ensaio, ou seja, da centralidade da figura do cholo nos projetos de sociedade de uma intelligentsia andina do século XIX e XX. Aliás, uma curiosa centralidade, posta a sua posição histórica de marginalidade que tão intrinsecamente marca sua situação social e seus traços psicológicos até os dias de hoje.

Para tratar do cholo, acho interessante trazer Aníbal Quijano para a discussão. Em seu ensaio de 1964, Quijano se debruça sobre o tema que seria o ponto de partida para suas discussões posteriores sobre a colonialidade do poder e desenvolve seu argumento a partir da noção de uma sociedade peruana como uma sociedade em transição - em oposição à ideia de uma sociedade de transição. 
Quijano faz esta distinção para enfatizar um borramento dos rumos desta transição, que tem início com a própria colonização e sua decorrente superposição de culturas. Em suas palavras, "la sociedad peruana se formó como un sistema de dominación social, por la superposición de los portadores de la cultura occidental española, sobre los portadores de la cultura incaica" (QUIJANO, 1980, p. 53). Para Quijano, é desta superposição de culturas que surgirá o próprio cholo, um sujeito de origem mestiça, sob influências culturais tanto indígenas quanto ocidentais espanholas - e, após a emancipação, também de outras potências ocidentais -, e que se vê diante de uma situação de tripla adesão cultural, ao mesmo tempo participando do mundo indígena, do mundo ocidental, e de um terceiro mundo que consiste no próprio mundo cholo que, entrelaçando os dois anteriores, acaba se transformando em algo diferente de ambos. Em um cenário de século XIX - e porque não dizer, ainda hoje , embora este processo de cholificação fosse visto frequentemente como tendo rumos claros tanto étnicos quanto culturais, ideológicos, econômicos e até raciais, o norte destas transições, como disse anteriormente, não era tão claro. E são várias as transições que se sobrepõem, entrelaçadas, e fazendo alegorias umas das outras, entre si. De acordo com Quijano, ao menos com relação ao Peru, o que havia e ainda há é uma concomitância entre o industrial e o pré-industrial, o moderno e o tradicional, sendo que o que se observa não é um caminhar em direção a um pólo ou outro, mas sim a criação de pólos terceiros, que se fundem em uma espécie de modernidade-tradicional chola, se é que o termo me é permitido.

Talvez fosse justamente diante deste cenário que o cholo começasse já em meados do século XIX a ser reconhecido como um importante personagem para a concepção de projetos de país para uma peruanidade que, como colocou o próprio Mariátegui, ainda não estava clara. Fosse em termos de um herói cholo libertador, fosse ele somente alegórico, ou ainda fosse o cholo apenas uma utopia a serviço de projetos políticos tidos como mais realistas do que ele próprio, fato era que a literatura começava a considerar o cholo mais seriamente. Na trama de Gorriti, notase que a choledad de seu herói é apresentada de forma não somente explícita como também bastante tensa na narrativa. Sua revelação à Rosa é difícil, e se apresenta através de um longo capítulo-mito fundador em que Hernán conta a Rosa seu grande segredo, não apenas sua choledad, mas também o fato de ser portador de uma das últimas chaves para o grande tesouro subterrâneo inca, passada de geração a geração até que chegasse o momento profético da libertação incaica e 
seu retorno ao poder. Em certo momento, Hernán relembra do momento em que sua mãe lhe revelara este grande segredo, já em seu leito de morte:

- Escucha, hijo mío, - dijo ella haciéndome sentar sobre sus rodillas... Las profecías de nuestro pais nos prometen un libertador que habiendo vivido largo tiempo entre nuestros enemigos, y aprendido de ellos las ciencias de las conquistas, romperá las cadenas de nuestra patria, y la dará mayor gloria y felicidad. Prométeme que tu serás ese libertador [...] (GORRITI, 1865, p. 33).

Se é bastante interessante a expectativa que Gorriti narra de um salvador inca intrinsecamente cholo, que transite entre "nuestros enemigos" e que depois retorne triunfalmente ao mundo indígena como seu libertador, mais ainda é a sequência da trajetória de Hernán que afinal, sabendo da suposta traição de sua amada durante sua ausência, abandona sem maiores cerimônias sua promessa inicial de libertação de seu povo e busca refúgio no seio acolhedor da Igreja Católica:

El amante engañado por su prometida, el corazón traicionado por un corazón que creyó tan puro y tan amante, recordó vuestro sublime llamamiento: 'venid a mí vosotros los que sufrís, que yo os consolaré' corrió a refugiarse en vuestro seno, y vos habéis cumplido vuestra promesa, lo habéis consolado y fortalecido (GORRITI, 1865, p. 43).

A posição de Hernán, confusamente deslocado ao longo da novela entre dois mundos, parece ser central para a definição de seu destino no Manchay Puytu gorritiano. São, aliás, não somente dois mundos, mas dois mundos submetidos a um terceiro, um mundo do amor romântico e que, mais do que os outros dois, tem centralidade clara não somente para a narrativa como para a tomada de decisões do nosso herói. Ora, se a tríade de mundos apresentada por Quijano encontra sua terceira via no mundo - ou na cultura - chola, aqui em Gorriti a terceira via chola parece equivaler afinal justamente a essa via do próprio amor romântico. Aliás, é justamente em função deste amor romântico - por uma moça de rica família branca, vale enfatizar - que Hernán rompe com o projeto inicial de sociedade que a novela parece apresentar de um cholo libertador do povo inca. Gorriti nega a profecia incaica que ela própria nos apresenta, parece de fato desejar sua realização - a narrativa da mãe para o filho em seu leito de morte, contando da passagem da chave por gerações é bastante comovente - mas se apresenta afinal inviável pela própria dupla-filiação de Hernán, cujo mundo afetivo dividido não parece permitir que se faça dele esse ideal de frio espião-libertador-profético inca. 
Mas é aí então que surge algo mais. Se Hernán de Camporeal rompe com o mundo indígena ao tornar-se sacerdote, seu reencontro dramático com Rosa em plena missa e a exumação de seu cadáver, como narra a própria Gorriti, são sacrilégios, e rompem também com o mundo branco-católico. Se Gorriti quer dizer algo com sua novela não é que o cholo possa ou não possa ser o libertador dos Andes. De fato, tampouco acredito que Gorriti enxergava grandes potenciais políticos no cholo andino de meados do século XIX. O cholo para Gorriti, arrisco-me a dizer, não passa de veículo literário, espécie de arquétipo do sujeito cosmopolita narrado por uma Gorriti, ela própria, cosmopolita, dividido em vários mundos e crenças e que, por fim, é esvaziado em prol de algo maior e "sem religião", no caso, o amor. Daí a dizer que a autora argentina pretendia falar do amor romântico como meio de superação desta dualidade andina entre o europeu e o indígena é somente um passo, que me parece, contudo, exagerado. Mais relevante do que isso é que Gorriti faz aqui, acima de tudo, a narrativa de um amor que termina tragicamente em função desta dualidade, seja religiosa, seja econômica - a divisão étnica andina se transformou também, ainda em tempos coloniais, em uma estratificação política e econômica de castas, segundo Quijano (1980) - e, portanto, era uma dualidade que tinha de ser superada. Como bem nota o especialista em literatura andina Keith Richards (1999), 'La quena' peca por seu caráter pouco etnográfico, com referências frágeis em relação à cultura quéchua, ainda que se trate de uma narrativa que guarde muitas complexidades dentro de si mesma. Esta fragilidade etnográfica, de qualquer forma, pode ser tomada como mais um dado relevante para se pensar justamente o caráter secularizante de sua obra. Negando ao cholo maior profundidade etnográfica, é como se Gorriti já sinalizasse que não pretende apostar em uma centralidade da cultura chola em seus projetos de nação boliviana - o fim de Hernán é confuso, e mesmo sua música, ainda que bela, é de difícil compreensão, "angel ó demonio, ¿quien era el autor de esa melodía?" (GORRITI, 1865 , p. 64). A ruptura, de qualquer forma, era o que se precisava consumar. Em seu capítulo de conclusão, Gorriti narra a efemeridade das coisas do mundo, que tudo renova. Mas a tragédia amorosa, ah, esta é perene:

El tiempo que incesantemente estiende su guadaña sobre la creación para destruirla y renovarla, y más que todo, el terror supersticioso, hicieron de aquel pueblo un desierto [...]. Pero ni los años, ni los omnipotentes rayos del Vaticano han podido borrar la memoria del amor infortunado y del estraño duelo del cura Camporeal, cuyos gemidos repite eternamente 
durante el silencio de las noches, en lo hondo de nuestros valles y en las plazas de nuestras ciudades la voz del instrumento que él consagró à su dolor, y al que los hijos del Perú dieron el nombre de Quena, palabras que en la quechua antigua significa: pena de amor. (GORRITI, 1865, p. 66).

\section{A VERSÃO DE PALMA E SUAS REPERCUSSÕES}

O círculo intelectual do qual Gorriti participava estava repleto de vários nomes reconhecidos da literatura tanto boliviana quanto peruana. Entre os escritores e pensadores próximos da autora saltenha, certamente se destacava o peruano Ricardo Palma. Nascido em Lima em 1833, envolvido desde jovem em atividades tanto políticas quanto literárias, era um dos frequentadores das célebres tertúlias organizadas por Gorriti durante suas idas para a capital peruana e, de acordo com Richards (1999), foi muito provavelmente assim que Palma entrou em contato com a tradição do Manchay Puytu, o que o levou mais tarde a escrever sua própria tradução da história, o Manchay puito, incluído como uma de suas Tradiciones peruanas, sua obra de renome.

A versão de Palma, contudo, contrasta significativamente com a da novela de Gorriti. Primeiramente, vale notar, o espaço de Palma para publicação estava restrito ao dos jornais e revistas que o publicavam, o que certamente foi determinante no fato de tratar-se não de uma novela, mas de um conto de poucas páginas. Mas as diferenças vão além. O autor limenho narra a história de Don Gaspar de Angulo y Valdivieso, um sacerdote bastante respeitado de Cuzco, marcado entre outras coisas por sua erudição - apresentado como um grande latinista e teólogo respeitado -, e que se vê um dia tomado por uma paixão arrebatadora pela jovem Anita Sielles. Incapaz de resistir à sua súbita paixão, o sacerdote resolve ir ao encontro de Anita "y la cantó de firme y al oído la letanía del cupido" e, poucas noites depois, como narra Palma sempre em seu inimitável tom de paródia, "fuese a hacer las delicias de la casa parroquial con no poca murmuración de las envidiosas comadres del pueblo" (PALMA, 1977, p. 239). Um dia, entretanto, o sacerdote é forçado a deixar a cidade por alguns dias para tratar de negócios e, no caminho de volta, é pego de surpresa pela notícia de que sua amada estaria doente, à beira da morte. Don Gaspar retorna a Lima, porém demasiado tarde, encontrando Anita já morta. Inconformado, como na novela de Gorriti, desenterra o corpo de sua amada e o leva para seu quarto, cobrindo-o de beijos, rasgando-Ihe a mortalha e trocando-a 
por um traje de carmesim, um colar de pérolas e brincos de pedras preciosas. Enfim, tomou sua quena e, de improviso, pôs-se a tocar o Manchay Puytu, e assim o fez por três dias e três noites, até ser encontrado agonizante, ao lado do corpo já decomposto de Anita.

O primeiro ponto a se notar é que a versão de Palma apaga quase que todo e qualquer traço de cultura indígena ou de choledad da história. Ao que tudo indica, tanto Anita quanto Don Gaspar eram brancos. Novamente, segundo Keith Richards, "su interés en la vida de los indios es insignificante. El Manchay-Puito de Palma es una versión tamizada culturalmente para un lector criollo, que no explora ni los aspectos indígenas del relato ni sus aspectos sexuales irregulares" (RICHARDS, 1999, p. 26-27). Palma não está preocupado com a origem indígena da tradição, e é curioso que, apesar de tomá-la a partir do contato que teve com a obra de Gorriti, não sente problemas em eliminar completamente da trama quaisquer traços incaicos, o que corrobora ainda mais com a idéia de que a presença do cholo em La quena não implicava qualquer depósito de expectativas sobre o cholo de um maior protagonismo no cenário político andino - repito, Palma retira o cholo de cena sem maiores problemas. Para o autor peruano, o importante era manter vigente um projeto de secularização e de modernidade que implicava por sua vez um afastamento da Igreja.

Talvez não fosse época para grandes divergências políticas e religiosas. Ao menos, Palma, com toda a sua notoriedade literária já estabelecida, não parecia se sentir à vontade para ofensivas mais agressivas neste sentido, de modo que seu principal instrumento narrativo de crítica era também, e ao mesmo tempo, aquilo que amortecia sua própria agressividade, ou seja, a paródia. É interessante notar neste sentido como diferentes autores se referem ao caráter paródico da obra de Palma. Para Tanner (1985), por exemplo, a literatura irônica de Palma servia a uma tentativa de desencantamento do mundo e então voltarmos à idéia de um projeto de secularização da sociedade peruana, enquanto que para Durán Luzio, Palma escreve para "acentuar los vícios de la colonia", ou seja, para "extirpar esa presencia de un legado que retardaba y dificultaba la implantación del sistema republicano en el Perú" (apud FOSTER; ALTAMIRANDA, 1997, p. 182). Assim, no Manchay-Puito palmiano notam-se trechos como aquele em que o autor narra o momento em que o respeitado sacerdote cede à bela moça: "Decididamente el cuerpo le pedía jarana..., y jvamos!, no todo ha de ser rigor. Alguna vez se le ha de dar gusto al pobrecito sin 
que raye en vicioso; que 'ni un dedo hace mano ni una golondrina verano'” (1977, p. 239).

E nota-se então que, nos dois parágrafos que se seguem à pequena concessão do rigor, Palma narra os seis meses de "arrullos amorosos" dos dois amantes e a viagem que Don Gaspar é forçado a fazer - e que culmina na morte de Anita -, motivada por negócios mal-encaminhados. Foster e Altamiranda (1997), por outro lado, comenta outros críticos literários que, em detrimento de elogiar o caráter didático da paródia palmiana, a criticam como uma limitação de sua escrita, retirando através da ironia todo o peso e dramaticidade das situações sociais que narrava. Mais interessante ainda para nosso ensaio, contudo, é a crítica de Mariátegui (2006) à literatura de Palma. De acordo com o autor, Palma aparece oficialmente como o representante máximo de uma literatura colonial e não como emblema de uma ruptura. Não deixade ser curioso que Mariátegui assuma para si essa posição de defensor do único escritor peruano a ter retirado completamente o protagonismo do cholo do Manchay Puytu, ou ao menos não é o que se esperaria vindo de um pensador que conferia centralidade ao povo indígena em seus projetos de sociedade, de socialismo e de Estado peruano. Contudo, há um contexto para esta tomada de postura e que deve ser compreendio. Tratava-se de um tenso e cauteloso duelo de forças. Se por um lado Palma não tinha condições políticas de realizar qualquer crítica mais frontal às instituições dominantes da época, por outro lado sua narrativa irônica tinha a leveza necessária para que pudesse penetrar politicamente sem ser censurada. Em última instância, para Mariátegui, Palma era o reflexo de um liberalismo peruano fraco tanto em consistência quanto em originalidade, e que cedeu as rédeas da revolução à própria elite colonialista. Nestas circunstâncias, não havia tanto que se pudesse fazer: "la sátira de las Tradiciones [Peruanas] no cala muy hondo ni golpea muy fuerte; pero precisamente por eso, se identifica con el humor de un demos blando, sensual y azucarado. Lima no podía produzir otra literatura" (colchetes meus) (MARIÁTEGUI, 2006, p. 190).

De fato, ao menos dentro do que este ensaio se propõe, mais interessante do que pensar a obra de Palma é pensá-la à luz dos projetos mariateguianos de sociedade. A leniência de Mariátegui em relação a Palma pode também ter outras razões. A centralidade indígena em Mariátegui era fundamental, mas também específica. Para a historiadora inglesa Nicola Miller (1999), Mariátegui dificilmente pensaria a questão indígena em termos de colocar o próprio indígena ou o cholo 
diretamente como portador solitário e revolucionário de um novo projeto de nação, como chega a parecer propor Gorriti em certos momentos. A partir do momento em que a questão indígena para Mariátegui se manifesta como sendo acima de tudo uma questão de classe - em sua visão, "any possibilities for the Indians to elevate themselves materially and intelectually are dependent upon a change on social and economic conditions. They are determined not by race, but by economics and politics" (apud MILLER, 1999, p. 160) - tem-se que os chistes irônicos de Palma em relação à aristocracia e a Igreja, classes dominantes do Peru republicano, ainda que originados em um ressentimento de uma mesocracia derrotada, também the interessam. Defende afinal - nunca é demais lembrar - uma luta que é, ainda que indígena, também estrutural e classista.

\section{A VERSÃO DE JORGE LIRA: CONTRASTES DE PROJETOS DE SOCIEDADE ANDINA}

De acordo com o padre cuzquenho Jorge Lira (1974), as versões do Manchay Puytu de Palma e Gorriti não seriam, porém, mais do que grandes deformações de uma versão cuzquenha original. Para Lira, "un cura sensual necrofílico, de monstruoso apasionamiento por una joven llamada Anita del pueblo de Yanakiwa, sustituyen al Kuraka y a Issicha Puytu, del texto auténtico". Sem querer entrar no mérito sobre a autenticidade de cada versão, o que vale destacar é que Jorge Lira fez de fato um grande e reconhecido trabalho de resgate de diversas tradições orais peruanas - e especialmente, em Cuzco - ao longo de vários anos. Com base em suas pesquisas, chega ao que considera como uma "versão definitiva" do Manchay Puytu e, no final da década de 40, o publica conjuntamente com José María Arguedas - que faz o trabalho de tradução do conto do quéchua para o castelhano. "Isicha puytu", como disse Lira, contudo, era bastante diferente de versões anteriores da tradição. A começar pela centralidade feminina do conto, protagonizado por Isicha, uma jovem indígena que servia ao ayllu ${ }^{1}$ do $k u r a k a^{2}$ local. Convocada para servir diretamente na casa do kuraka, a beleza de Isicha acaba por fascinar o seu senhor. Nas regras do ayllu, cada mulher passa um turno em cada função, e depois deve passar a uma função de trabalho diferente, e assim por diante. Ao fim de seu turno de trabalho em sua casa, contudo, o kuraka decidiu não permitir que Isicha retornasse para casa. É interessante a forma como a convocação 
marca a entrada de Isicha dentro do mundo colonial espanhol, e as tensões que daí decorrem parecem típicas do processo de cholificação descrito por Quijano. Assim, quando os irmãos de Isicha, estranhando seu sumiço, vêm à casa do kuraka para saber de seu paradeiro, acabam rejeitados pela irmã, que se nega até mesmo a reconhecê-los como parentes. Isicha rejeita suas origens étnicas - de fato, chega mesmo a esquecê-las por completo - em função de suas ambições de entrada no mundo dos brancos, mas o mundo dos brancos também a rejeita e a personagem passa a viver numa espécie de limbo étnico em que seus laços sociais, subitamente, se perdem em função deste laço único e apaixonado entre Isicha e o kuraka. Enfim, o kuraka tem de viajar e deixa sua amada aos cuidados de seus servos. $\mathrm{Na}$ ausência de seu senhor, porém, os servos, que odiavam a Isicha, resolvem que não deveriam servi-la, afinal, “¿quién ha de cuidar de esa mujer? ¿Quién ha de querer alcanzarle nada?" (LIRA, 1974, p. 160).

Isicha morre na solidão de seu sono, rejeitando sua família que agora dela também já não se lembrava, e rejeitada por seus criados. A posição de Isicha, uma indígena que se torna senhora, como uma branca, na casa de um kuraka, aparece no conto recolhido por Lira como insustentável, tanto socialmente quanto psicologicamente. A sequência final da história de Isicha é riquíssima em simbolismos. O kuraka retorna e, não aceitando a morte de sua amada, trata seu corpo como se ainda estivesse vivo. E Isicha, ao cabo de três dias, aparentemente retorna a vida, ainda que de certa forma ausente, incapaz de fazer a maior parte das coisas que fazia. Quando então o kuraka tenta "pecar" com sua amada, Isicha subitamente se transforma em asno - de acordo com Richards (1999), lugar-comum das relações sexuais ilícitas. O kuraka, feliz por não ter de enterrá-la, leva o asno para ter seus cascos devidamente ferrados, no que Isicha novamente se torna mulher, e agora afirma ter morrido desde o início em função de ter negado seus pais, e depois, tornado-se asno em função do pecado que iria cometer seu amante com seu corpo inerte. Mais do que em qualquer outra versão do Manchay Puytu, a narrativa aqui descreve uma sequência de quebra de tabus, da negação dos pais até a necrofilia e a zoofilia. Isicha, por sua vez, entra em um estado de existência latente, alternando entre vida e morte, em uma ambiguidade ontológica que é também novamente a ambiguidade chola. Tomando emprestado à nossa análise os termos de Mary Douglas (1991), a narrativa de Lira parece levar o cholo a condições de impureza extremadas, em um acúmulo de rupturas de laços que se transforma 
em ruptura moral não só para si, como do mundo no qual passa a viver. Em seu auge da insustentabilidade, torna-se enfim inarrável, inclassificável, e sua transformação em asno parece ser necessária justamente para tornar possível a continuação de uma narrativa de outra forma moralmente inviável. Isicha ainda volta a morrer e ser enterrada, antes de ser novamente desenterrada pelo kuraka e de enfim desaparecerem, os dois, "y se fueron no sabemos dónde" (LIRA, 2006, p. 164). Tem-se afinal que o mundo dos brancos, representado pela autoridade máxima do kuraka, sequer permite que Isicha retorne ao mundo indígena. O kuraka aqui é o poder que oprime, mas que também atrai. Não há fuga possível para Isicha, mas também não há fuga permitida.

Já não se trata mais no conto recolhido por Lira de narrar um novo projeto de nação para o Peru através da literatura, escrita ou oral. Em um mundo andino, que buscava novos rumos e já debatia com autores como Arguedas e Quijano as possibilidades políticas de um projeto indígena naquela sociedade, trata-se aqui de pensar a própria condição do cholo neste cenário, bem como na própria mitologia que seguia atualizando suas tradições orais ao longo do tempo. E que parecia, narrar cada vez mais, um cholo sem lugar, sem laços, quase uma personificação da transição peruana descrita por Quijano, preso entre um ponto e outro, caminhando, porém, para um terceiro, ainda inefável. Ao final da narrativa de Lira, a chola por fim desaparece. Mas para onde?

\section{A VERSÃO DE TABOADA TERÁN: O CHOLO E A COLONIALIDADE DO PODER}

Sem dúvida, porém, a adaptação escrita do Manchay Puytu que mais se aproxima das idéias de Aníbal Quijano sobre o cholo e a colonialidade do poder pertence ao escritor e historiador pacenho Nestor Taboada Terán. Editado pela primeira vez durante seu exílio na Argentina em 1977, "Manchay Puytu, el amor que quiso ocultar Dios" (1981) contrasta com todas as anteriores, tanto por seu tamanho, como por sua densidade etnográfica.

Taboada conta a história de um jovem sacerdote católico de ascendênckia indígena, Padre Antonio de la Asunción, que mantém relações ilícitas com sua criada, María Cusilimay, também indígena. A base do Manchay Puytu de Taboada, de fato, se assemelha bastante a de versões anteriores, até porque o autor pacenho 
faz questão de tomar várias delas como referência, inclusive as de Gorriti e Palma. Assim, María também adoece durante uma viagem do sacerdote a Lima, e também acaba falecendo antes do seu retorno. Padre Antonio, ao chegar de viagem, também se recusa a aceitar a morte de sua jovem amada, leva seu corpo para casa, 0 perfuma e veste, como que crendo que isto poderia trazê-la de volta à vida. Percebendo que suas tentativas falhavam, retira de sua amada uma tíbia, com a qual faz uma flauta, uma quena. Seus lamentos, demasiado tristes através do som da quena, passam a ser cantados dentro de um imenso cântaro (puytu) para atenuar seu som melancólico. Enfim, morre como pária, rechaçado tanto por índios como por brancos. De acordo com Richards:

\footnotetext{
El ha traicionado a la causa india por ayudar a la expansión del credo cristiano, quizá el arma más poderosa del invasor, pero también ha burlado las enseñanzas de la Iglesia Católica del cual era membro; finalmente, es enterrado en el lugar de sus pecados. (1999, p. 23).
}

Semelhanças à parte é interessante notar as adaptações que Taboada faz no seu Manchay Puytu em relação às versões anteriores. Podemos começar pelo cenário, fugindo da Lima de Gorriti e Palma e nos transferindo para uma Potosí colonial marcada tanto pelas riquezas que tanto atraíram aos colonizadores e exploradores da época, quanto pelo seu cosmopolitismo. Com sua riqueza de minérios aparentemente infindável, Potosí era também esse espaço de milagres que auto-justificavam a santidade do mercantilismo colonial europeu, e que criavam a possibilidade ao indígena de ingresso nas escadas de ascensão - ao menos econômica - do mercantilismo através das portas abertas da prata. É interessante notar como a mitificação de Potosí, oriunda de tempos pré-colombinos, serve bem a uma posterior mitificação mercantilista. De acordo com Francovitch:

\footnotetext{
El mito de Potosí está vinculado al culto ancestral de las montañas. Pero en Potosí, a la imagen de la montaña como expresión de la vida cósmica predominante en la mitología precolombina, se sobrepuso la del misterioso poder minero. El cerro dejó de ser una "huaca" o un "achachila" protector para convertirse en el caprichoso dispensador de los tesoros fabulosos escondidos en su seno. (apud RICHARDS: 1999, p. 20).
}

Se Potosí deve muito de seu cosmopolitismo e sua mestiçagem a sua era colonial de extração frenética de minérios, o desenvolvimento da indústria extrativa também será fundamental historicamente, de acordo com Quijano (1980), para o 
desenvolvimento de um processo mais intenso de cholificação no Peru. Gerado subitamente como que uma nova ordem de centralidades econômicas e urbanas na região, o estabelecimento desta indústria após o fim da primeira guerra "desencadenó una serie ininterrumpida de procesos de cambio, consistentes principalmente en la aparición de nuevos núcleos urbanos, de poblaciones aluviónicas, sin tradición feudal o indígena, así como el lento pero efectivo proceso de modificación de los patrones culturales y sociales en las ciudades tradicionales" (QUIJANO, 1980, p. 82-83). Repentinamente, grandes camadas de populações indígenas passaram a ver na mineração uma alternativa para o ganho de meios de sobrevivência. Como em Potosí, o acesso à ascensão econômica parecia mostrar-se visível nos brilhantes metais preciosos das montanhas andinas, ao mesmo tempo que forçando o seu contato próximo com o branco. Tanto na Potosí colonial de Taboada quanto no Peru industrial de Quijano, as minas eram controladas pelos brancos, e juntamente com a substituição da idéia dos cerros achachilas por um cerro dispensador de ouro e prata, os valores indígenas também se viam forçados a adaptar-se aos ideais de ocidentalidade que se apresentavam.

Não surpreende, assim, que Taboada tome a Potosí colonial como cenário para um Manchay Puytu que se propõe justamente a pensar este processo de mestiçagem, seus sincretismos e suas tensões. Ao contrário de outros autores, Taboada se mostra de certa forma otimista em relação à cholificação. Apresenta em sua narrativa uma Bolívia de uma multiculturalidade que se resolve, ao longo da trama, em bem elaborados conjuntos de sínteses entre os personagens, e que vai aos poucos como que fabricando o cholo dialeticamente, hegelianamente, em teses e antíteses brancas e indígenas que gradualmente levam à formação e de uma nova e independente consciência/entidade americana. Assim, se Taboada usa o personagem de Bigardo como representante alegórico do conquistador espanhol, faz-Ihe oposição o personagem de Ñauparruna, personificação do passado indígena (ñaupa, do quéchua "antigo"; e runa, também do quéchua "gente"), criado pelo autor dentro de uma tradição cosmológica quéchua de deuses com atributos similares, que vagam pelo mundo pronunciando conselhos e juízos a partir da onisciência da memória de seu povo (RICHARDS, 1999). Finzi e Selvagini (2002) também concordam com esta análise. Para eles, ambos constituem juntos, na narrativa de Taboada, a personalidade composta do Padre Antonio "che come tesi ed antitesi rappresentano rispettivamente il popolo indio e quello ispanico, dai quali nascerà 
come sintesi 'el Hombre Americano', di cui l'autore stesso si sente fortunata e vitale espressione" (FINZI; SELVAGINI, 2002, p. 399). A relação do sacerdote com Ñauparruna é particularmente interessante. Nauparruna aparece em certos momentos como um nacionalista radical, em outros como xamã, e até na figura de um nobre catalão. Sua habilidade em metamorfosear-se é essencial para sua longevidade, tal como foi para as culturas indígenas oprimidas pela colonialidade (RICHARDS, 1999) e que sobreviveram através da adaptação - e da própria cholificação.

Mas o que afinal Taboada espera do cholo? Como no cholo de Gorriti, aparece em certos momentos a idéia de um cholo cosmopolita, cuja capacidade de transição entre dois mundos Ihe serve estrategicamente, em Gorriti como forma de tomar para si as estratégias de conquista dos espanhóis em prol da causa incaica rumo a uma profética libertação, e em Taboada, para servir como uma espécie de interlocutor entre os dois mundos. Mas se a perspectiva romântica de Gorriti é negada por ela própria ao longo de sua novela, a perspectiva mediadora de Taboada é narrada desde o princípio como ilusória. Padre Antonio, enquanto intermediário, é uma ferramenta da colônia. Quando um grupo de insurgentes indígenas invadem Potosí e reclamam que Tupac Amaru II seja reconhecido como descendente legítimo do império peruano, é Padre Antonio quem os censura em nome de Deus. A conversa entre as duas partes é longa, e enfim, a própria condição do cholo de mobilidade entre o mundo branco e o mundo indígena cai derrotada quando um dos indígenas o afronta. Deveria falar em espanhol, e não em quéchua. "Para hablar, no necesitas prestarte otra lengua, tatacura [...]. Háblanos em Runasimi" (TABOADA TERÁN, 1981, p. 176).

\section{A FORMAÇÃO DIALÉTICA DO CHOLO EN TABOADA TERÁN}

Sem querer me aprofundar no tema além do que o espaço aqui me permite, é interessante pensar a proposta de Taboada de um cholo formado dialeticamente, através de Ñauparrunas e Bigardos. Quando escreveu "Pele negra, máscaras brancas" (1983), o psiquiatra e filósofo antilhano Frantz Fanon, ainda que pensasse mais especificamente sobre a condição colonial do negro, trouxe consigo algumas posições sobre a própria condição colonial em si e que podem ser interessantes para nossa discussão. Ora, entre outras coisas, o que Fanon faz em sua obra é 
justamente romper com a noção de uma dialética colonial fundante do colonizado. $\mathrm{O}$ colonizado está ao mesmo tempo fora de lugar e ocupando vários lugares. Transita entre espaços em que se aproxima de sua identidade original - de negro, ou de indígena -, e espaços em que veste a máscara de submissão perante o branco. Ao transitar, contudo, o colonizado produz modulações, multiplica suas possibilidades de máscaras, de subjetividades, multiplica seus espaços e, consequentemente, também explodindo a noção dual de dialética e qualquer decorrente possibilidade de síntese (CORSINI, 2006).

A postura de Fanon em relação à colonialidade não é muito diferente, ao menos neste ponto, da de Quijano. Também para Quijano, o cholo, se por um lado se constitui através da tensão entre dois pólos mais ou menos dialéticos modernidade e tradição, Bigardo e Nauparruna -, sua noção de sociedade de transição, como já comentamos antes, se opõe a ideia que parece estar presente em Taboada de uma caminhada evolutiva, de caminhos bem iluminados, rumo ao consenso final. Ao contrário, olha-se para frente em Quijano e nada se enxerga além do fato de que há um caminho e que por ele se segue. Quando escreveu este ensaio, contudo, nos idos de 1964, Quijano já vislumbrava uma identidade chola que começava a se formar de modo mais consistente, e mais do que isso, deixando a ideia de inferioridade que se forma, quando se tenta subir as escadas sócioeconômicas criadas pela colonialidade do poder (QUIJANO, 2000), e afirmando-se, enfim, enquanto categoria à parte de brancos e indígenas. Segundo Quijano,

\begin{abstract}
en la literatura peruana, especialmente la narrativa, los cholos aparecen como poseedores de un grado notable de autoidentificación como grupo aparte (Alegría, Arguedas, Sueldo Guevara, Ribeyro). Por otra parte, la evolución del cancionero popular peruano, tanto urbano como campesino, presenta de manera creciente el tema del cholo, de su situación social ambivalente, pone énfasis en un cierto orgullo de ser cholo, ridiculiza con frecuencia la imitación del estilo de vida criollo, satiriza abiertamente los regímenes políticos de manera distinta que los miembros de la clase media urbana pobre, y el cancionero sentimental o romántico popular está impregnado de la cazurrería y escepticismo que en la opinión general, son propias de la personalidad chola. (QUIJANO, 1980, p. 68).
\end{abstract}

É interessante pensar por alguns instantes a centralidade do cholo - ou do mestiço em geral - não somente neste ensaio de Quijano, mas em toda a discussão que realiza em torno do conceito de colonialidade do poder. O cholo, como ele mesmo diz, é um sujeito que se encontra no limbo da participação de um universo cultural triplo - branco, indígena e cholo -, ao mesmo tempo em que participando 
somente de forma parcial em cada um deles (1999). A adesão histórica, sempre parcial, a uma cultura ocidental acontece estrategicamente em uma situação de dominação do indígena perante os poderes coloniais. A colonialidade do poder reprime a manifestação de signos indígenas e condiciona a participação deste poder à manifestação de signos brancos (1991). Partindo desta análise, se Quijano deposita no cholo expectativas de agente transformador fundamental para os rumos da sociedade de transição peruana - e de sociedades coloniais em geral -, é por também ver no grupo cholo, um grupo de pulsões tanto ocidentalizantes quanto de retorno ao mundo indígena, negadas, bloqueadas, tornadas insustentáveis por sua posição de ambiguidade perante ambas as sociedades. Trata-se em Quijano, creio, da compreensão de que há um lócus privilegiado na posição do cholo como sujeito ao mesmo tempo reprimido por um lado, mas ainda assim capaz de atuar, por outro lado, como interlocutor entre estes dois mundos em tensão. Reduzido à marginalidade, mas também nela refugiado, o cholo teria ampla margem de liberdade de conduta para atuar como esta terceira via de descolonização perante o poder colonial.

\section{CONCLUSÃO}

Se em Quijano a identidade chola parte de sua histórica instabilidade para uma necessária estabilização em sua afirmação enquanto classe social, Fanon (1983), por sua vez, ao falar sobre o negro, fala em instabilidade do sujeito como estratégia de resistência. Fanon quer a multiplicidade de lugares e identidades, quer caminhos tortos e difusos que não possam ser localizados, quer fugir da tripla-pessoa que the é imposta pelo branco, pela presença do branco, fugir da dualidade inferioridaderesistência que a relação colonial com o branco the impõe e, enfim ser outro, identificado fora desta dualidade. É o dilema entre a identidade que organiza a agência, e a fuga identitária, infinitamente reconstruída, infinitamente deslocalizada, e que liberta a própria agência.

Mas após este fértil diálogo com Quijano e Fanon, retornemos então ao Manchay Puytu de Taboada Terán. A construção dialética de sua narrativa, como já afirmei antes, parece indicar a aposta de Taboada em um projeto de nação que caminha, através de tortuosas teses e antíteses, rumo ao consenso, sendo o cholo o inevitável portador desta síntese. Contudo, quando trazemos esta dialética de 
constituição do social da obra para a esfera do psicológico, eis que encontramos algo novo. Em comum entre todas as versões e traduções do Manchay Puytu é o uso narrativo da sexualidade como um adversário, às vezes mais trágico, às vezes mais irônico, mas sempre um adversário da lgreja, e junto com ela, da elite colonial proto-republicana que a acompanhava. Mas a opressão da sexualidade, jogada nas profundezas do id, é também uma parte da opressão colonial perante o indígena. Padre Antonio, como o Hernán de Gorriti, essa composição tragicamente mestiça do sacerdote apaixonado, são sínteses alegóricas, também, da tensão, exacerbada literariamente, entre colonialidade e sexualidade. Se o sexual é emblemático das pulsões reprimidas que compõem o id da psique ocidental, aqui o id é composto, também, pelo elemento indígena, ambos equiparados e confundidos em sua condição de pedaço reprimido do eu-cholo. Ñauparruna e Bigardo, trazidos ao nível da psique chola do Padre Antonio, compõem também uma dialética e inevitavelmente tensa relação entre id e superego, entre os quais perambula quase esquizofrenicamente o personagem ao longo da trama. Termina ainda preso nesta espécie de esquizofrenia cultural, fabricando uma cosmologia meio cristã, meio quéchua, enquanto tenta resgatar a vida de sua amada. Segundo Neustadt:

\footnotetext{
Ainda que o sistema de crenças do inca faça a mediação do esforço do Padre Antonio para comunicar-se com o espírito de María, sua visão da ressureição resulta de sua interpretação literal das escrituras da bíblia: "Tomaba al pie de la letra la verdad evangélica", diz o padre, "para no equivocarme em la predicación”. "¿Era una ruin mentira la resurrección de los muertos?", implora quando ela não retorna à vida. (NEUSTADT, 2007, p. 105).
}

Não parece haver para Taboada conciliação psicológica possível entre o euindígena, o eu-sexual e o eu-sacerdote. A tríade da cholificação se mostra insustentável, e a morte de María Cusilimay também de certa forma lhe serve de metáfora, é o fracasso de Padre Antonio. Taboada parece afinal ver de forma bastante distinta as possibilidades sociais do cholo e sua realidade psicológica. $\mathrm{O}$ fim trágico do cholo de Taboada, porém, ainda traz ao Padre Antonio uma última solução libertadora. O yaraví do Manchay Puytu é a ruptura final com o mundo cristão e com a própria modernidade - é interessante notar como ele caminha, com o corpo exumado de sua amada, passando do centro moderno da cidade de Potosí, cheio de ruas retas e largas, rumo às suas ruas estreitas e tortas, contraposto emblemático dos ideais de civilização para o imaginário urbano local (RICHARDS, 
1999). Mais do que isso, Taboada relembra em Antonio o simbolismo quéchua da quena com a qual o padre tenta, em seu desespero, ressucitar a amada. $\mathrm{Na}$ cosmologia quéchua, a quena é um canal através do qual se sopra a fala dos mortos. Em última instância, o Manchay Puytu de Taboada, e provavelmente também muitas de suas traduções tradicionais, mais do que qualquer projeto de nação, carregam consigo o projeto de lembrança de um traumático passado colonial. É necessário soprar a quena, afinal, para fazer o passado falar.

\section{NOTAS}

1 Ayllu: termo de origem quéchua, se refere à família ou parentesco, mas se trata mais especificamente de uma forma tradicional de organização comunitária para o uso da terra, e que de certa forma se mantém mesmo durante o período colonial.

${ }^{2}$ Kuraka:também do quéchua, equivale ao governador principal de uma província, especialmente na região do Tawantisuyu.

${ }^{3}$ Achachila: do aymara, trata-se de divindade das montanhas, especialmente em Potosí.

\section{REFERÊNCIAS}

BERG, Mary. GORRITI, Juana Manuela. In: MARTING, Diane (Org.). Spanish American women writers: a bio-bibliographical source book. Connecticut: Greenwood Press, 1990.

COCIMANO, Gabriel. La tradición oral latinoamericana: las voces anónimas del continente caliente. UACJ, Sevilla, n. 16, v. 2, 2006.

CORSINI, Leonora. Repensando a identidade no contexto das migrações. Psicol. Soc., v. 18, n. 3, Porto Alegre, set./dez. 2006.

DOUGLAS, Mary. Pureza e perigo. Lisboa: Edições 70, 1991.

ESPINO Relucé, Gonzalo. Manchay puytu y narrativas de la aldea letrada quéchua (La tradición escrita, siglo XIX). Universidad Nacional Mayor de San Marcos, Lima, n. 30-32, 2002.

FANON, Franz. Pele negra, máscaras brancas. Rio de Janeiro: Fator, 1983.

FINZI, Alessandro; SELVAGGINI, Luisa. Tra leggenda e romanzo: "Manchay Puytu. El amor que quiso ocultar Dios". Atti del XX Convegno A.ISP.I. Domenico Antonio Cusato, Loretta Frattale (Coord.), 2002, p. 389-400. 
FOSTER, David William; ALTAMIRANDA, Daniel. From romanticism to modernismo in America Latina. New York and London: Garland, 1997.

GORRITI, Juana Manuela. Sueños y realidades. Buenos Aires: Imprenta de Mayo de C. Casavalle, 1865.

LIRA, Jorge A. Issicha Puytu. Cuzco: Editora Mila Batres, 1974. . Issicha Puytu. In: ROMERO, Adolfo Cáceres. Narrativa quéchua del Tawantisuyu. Buenos Aires: Colihue, 2006.

MARIÁTEGUI, José Carlos. Siete ensayos de interpretación de la realidad peruana. Rosario: Kolectivo Editorial "Ultimo Recurso", 2006.

MILLER, Nicola. In the shadow of the state: intellectuals and the quest for national identity in twentieth-century Spanish America. New York and London: Verso, 1999.

NEUSTADT, Robert. Tocando os ossos do trauma colonial no romance Manchay Puytu de Nestór Taboada Terán. Caligrama, Belo Horizonte, n. 12, p. 85-111, 2007.

PALMA, Ricardo. Cien tradiciones peruanas. Caracas: Biblioteca Ayacucho, 1977.

QUIJANO, Aníbal. Colonialidad del poder y clasificación social. Journal of World Systems Research, Special Issue: Festchrift for Immanuel Wallerstein, Part I, v. VI, n. 2, Summer/Fall, 2000, p. 342-386. 1991, p. 11-20.

. Colonialidad y modernidad/racionalidad. Perú Indígena, v. 13, n. 29, Lima, Dominación y cultura: lo cholo y el conflicto cultural en el Perú. Lima: Mosca Azul Editores, 1980.

. Notas sobre a questão da identidade e nação no Peru. Revista de Estudos Avançados, v. 6, n. 16, São Paulo, 1992, p. 73-80.

RICHARDS, Keith. Lo imaginario mestizo: aislamiento y dislocación de la visión de Bolívia de Nestór Taboada Terán. La Paz: Plural Editores, 1999.

TABOADA TERAN, Nestor. Manchay Puytu, el amor que quiso ocultar dios. Cochabamba: Editorial Los Amigos del Libro, 1981.

TANNER, Roy. The humor of irony and satire: in the Tradiciones Peruanas. Columbia: University of Missouri Press, 1985. 